\title{
Prevalence of subjective symptoms among hospital pharmacists and association with drug compounding practices
}

\author{
Ryoichi INABA $^{1 *}$, Atsushi HIOKI ${ }^{1,2}$, Yoshihiro KONDO ${ }^{1}$, \\ Hiroki NAKAMURA ${ }^{3}$ and Mitsuhiro NAKAMURA ${ }^{4}$ \\ ${ }^{1}$ Department of Occupational Health, Gifu University Graduate School of Medicine, Japan \\ ${ }^{2}$ Matsunami General Hospital, Japan \\ ${ }^{3}$ Gifu Research Center for Public Health, Japan \\ ${ }^{4}$ Laboratory of Drug Informatics, Gifu Pharmaceutical University, Japan \\ Received May 27, 2013 and accepted August 28, 2014 \\ Published online in J-STAGE September 13, 2014
}

\begin{abstract}
In Japan, the principal role of hospital pharmacists has changed from that of dispensing medicines for outpatients to provision of clinical pharmacy services for inpatients. A selfadministered questionnaire about subjective symptoms, working patterns, work environments and job satisfaction was administered to 495 hospital pharmacists and 84 prefectural office-based pharmacists (control group). The response rates were $63.4 \%$ and $90.5 \%$, respectively. Hospital pharmacists showed a higher prevalence of nasal symptoms than that shown by the control officebased pharmacist group. The prevalence rate of nasal symptoms was lower only in male pharmacists who worked in a dispensary equipped with dust collector. The prevalence of symptoms noticed by hospital pharmacists and community pharmacists after starting drug compounding practices was also compared. The prevalence of subjective symptoms that pharmacists noticed after starting drug compounding was lower in hospital pharmacists than in community pharmacists. Job satisfaction was lower in hospital pharmacists than in office-based pharmacists; however, there was no clear association between the subjective symptoms reported and job satisfaction. Further studies on removal effect of drug dust in a dispensary and symptoms in individual pharmacy facilities are needed.
\end{abstract}

Key words: Subjective symptoms, Questionnaires, Hospital pharmacists, Drug compounding, Work environments, Occupational exposure

\section{Introduction}

The principal role of hospital pharmacists in Japan has changed from drug compounding works for outpatients to total inpatient care as a member of the medical team ${ }^{1,2)}$.

*To whom correspondence should be addressed.

E-mail: rinaba@gifu-u.ac.jp

(C)2015 National Institute of Occupational Safety and Health
Drug compounding and filling of prescriptions for outpatients have been transferred to dispensing pharmacists in community pharamacies $^{3}$. We previously reported that many pharmacists working in community pharmacies developed allergic or irritation symptoms of the eyes, nose, oral cavity, and throat, which they noticed after starting drug compounding practices ${ }^{4)}$.

No study has recently investigated the influences of drug compounding practices on subjective symptoms 
among hospital pharmacists in Japan, although nasal allergies in hospital pharmacists were reported previously ${ }^{5,6}$. Specific warnings are issued to medical staff handling antineoplastic drugs to prevent occupational exposure because these drugs can have harmful properties such as mutagenicity, teratogenicity, or carcinogenicity ${ }^{7-9)}$. In other countries, contact dermatitis ${ }^{10,11)}$ and sensitization ${ }^{12)}$ of health care workers (nurses and pharmacists) to drugs other than antineoplastic ones are also reported recently. The ratio of the elderly inpatients to total inpatients has increased in Japanese hospitals. The percentages of inpatients aged $65 \mathrm{yr}$ and above were $38.8 \%$ in $1984,48.2 \%$ in $1993,60.4 \%$ in 2002 , and $68.2 \%$ in $2011^{13}$. Elderly people often have several diseases and need various kinds of medicines ${ }^{14)}$. The degrees of pharmacists' exposure to medicine is likely to be different, depending on whether the pharmacist is hospital or community-based, and on the clinical activities of the hospitals and clinical departments.

In order to investigate the influences of drug compounding practices to subjective symptoms, we investigated the prevalence rates of subjective symptoms among hospital pharmacists and compared them to previously reported prevalence rates among community pharmacists ${ }^{4}$ by using self-administered questionnaires.

\section{Subjects and Methods}

We conducted a cross-sectional study by mailing anonymous self-administered questionnaires to study subjects from September 2012 to October 2012. All hospital pharmacists who were members of "A" prefecture society of hospital pharmacists in the Tokai region of Japan and all the members of "A" prefectural office-based pharmacists were included in the study as the study and control groups, respectively. Of 495 hospital pharmacists and 84 officebased pharmacists, 314 (63.4\%) and 76 (90.5\%) completed the questionnaire, respectively.

In this study, we also compared the prevalence rate of subjective symptoms that pharmacists had noticed since they started hospital-based drug compounding practices with that of community pharmacy-based dispensing pharmacists, investigated from June through July 2009 and already reported ${ }^{4}$. The monthly average air temperature and average relative humidity in a central city during the period of questionnaire survey were as follows: $23.4{ }^{\circ} \mathrm{C}$ and $62 \%$ in June $2009 ; 26.2{ }^{\circ} \mathrm{C}$ and $75 \%$ in July 2009 ; $25.5^{\circ} \mathrm{C}$ and $71 \%$ in September 2012 ; and $19.0^{\circ} \mathrm{C}$ and $62 \%$ in October $2012^{15)}$.

\section{Questionnaire}

The questionnaire included questions regarding (1) subjective symptoms, (2) symptoms that respondents noticed after starting drug compounding practices, (3) major role at the workplace, (4) the three clinical departments that the pharmacists was mainly involved in dispensation for, (5) frequency of crushing tablets, (6) procedures for crushing tablets, (7) frequency of opening capsules, (8) compounding processes and types of drugs that pharmacists considered related to their symptoms, (9) countermeasures against symptoms and the effectiveness of the countermeasures taken, (10) use of masks and gloves during drug compounding, (11) dust collector setting in the dispensary, (12) number of beds in the hospital, (13) history of drug compounding, (14) history of allergies and other diseases, (15) self-rated satisfaction with work, and (16) other socio-demographic factors.

Subjective symptoms listed in the questionnaire were: "an uncomfortable feeling, itching, or pain in the eyes"; "sneezing, or nasal discharge or obstruction"; "an uncomfortable feeling, itching, or pain in the oral cavity"; "an uncomfortable feeling, itching, or pain in the throat"; "a feeling of airway obstruction or dyspnea"; "skin irritation, itching, or flare"; "headache"; "nausea, vomiting, abdominal pain, or diarrhea"; "arthralgia"; "edema of the extremities"; "fever"; "anxiety or helplessness"; "general fatigue"; "palpitation or chest discomfort"; "numbness or dimmed vision"; and "others".

The question (3) regarding a pharmacist's major role in the hospital was classified into four categories: "drug compounding", "ward pharmacy services", "management", and "others". For the question relating to the procedures of crushing tablets (6), respondents could select "a tablet crusher for exclusive use", "mortar", "tablet cutter", "domestic coffee mill", and "others". Compounding processes that pharmacists believed to be related to the symptoms (question 8) were classified as follows: "powder drug compounding", "tablet crushing or capsule opening", "ointment preparation", "other operations", and "unknown". The types of drugs that they believed to be related to the symptoms were categorized as "antibiotics", "antineoplastic drugs", "antirheumatic drugs", "antipyretics", "metabolic disease drugs", "gastrointestinal drugs", "cardiovascular or respiratory drugs", "psycho-neurological drugs", "Kampo herbal preparations", "decoctions", "other drugs", “and unknown".

The question regarding history of disease (question 14) included the following options: "food allergies", "asthma", "atopic dermatitis", "urticaria”, “eczema”, "hay fever”, 
Table 1. Characteristics of the study subjects

\begin{tabular}{lcc}
\hline & $\begin{array}{c}\text { Hospital } \\
\text { pharmacists }\end{array}$ & $\begin{array}{c}\text { Prefectural office-based } \\
\text { pharmacists }\end{array}$ \\
\hline Number & 314 & 76 \\
Mean ages (SD) & $38.3(11.3)^{* *}$ & $43.9(10.9)$ \\
Male / female ratio & $0.96: 1^{* *}$ & $3.22: 1$ \\
Past history & & \\
Urticaria & $11.8 \%$ & $9.2 \%$ \\
Pollenosis & $6.1 \%$ & $10.5 \%$ \\
Atopic dermatitis & $5.7 \%$ & $3.9 \%$ \\
Asthma & $4.5 \%$ & $7.9 \%$ \\
Eczema & $4.1 \%$ & $5.3 \%$ \\
Prevalence rate of subjective symptoms & & \\
Sneezing, or nasal discharge or obstruction & $33.1 \%{ }^{*}$ & $21.1 \%$ \\
An uncomfortable feeling, itching, or pain in the eyes & $21.3 \%$ & $28.9 \%$ \\
Headache & $15.9 \%{ }^{*}$ & $26.3 \%$ \\
An uncomfortable feeling, itching, or pain in the throat & $15.3 \%$ & $6.6 \%$ \\
General fatigue & $13.4 \%$ & $13.2 \%$ \\
Skin irritation, itching, or flare & $10.8 \%$ & $6.6 \%$ \\
An uncomfortable feeling, itching, or pain in the oral cavity & $7.3 \%$ & $2.6 \%$ \\
A feeling of airway obstruction or dyspnea & $2.2 \%$ & $2.6 \%$ \\
\hline
\end{tabular}

$* p<0.05, * * p<0.01$ vs. prefectural officie-based pharmacists by $t$-test or Mantel-Haenszel test categorized by sexand age-groups: $24-39,40-49$ and $\geq 50 \mathrm{yr}$.

"cutaneous drug eruption", "hypertension", "heart diseases", "peptic ulcer", "diabetes mellitus", "liver diseases", "kidney diseases", and "other diseases".

The options provided for countermeasures against symptoms (question 9) were as follows: "use of a mask", "job replacement", "change of working place", "improvement of equipment", "other measures", and "nothing done".

Self-rated satisfaction with work (question 15) was assessed based on selection of one of four following categories: "dissatisfied", "somewhat dissatisfied", "somewhat satisfied", and "satisfied".

\section{Statistical analysis}

Statistical significance of differences in continuous data was assessed using the unpaired $t$-test. Proportions were compared between hospital pharmacists, between hospital pharmacists and office-based pharmacist (controls), and between hospital pharmacists and community pharmacists by using the Pearson's $\chi^{2}$ test or Mantel-Haenszel procedure with stratification by age group or by sex and age groups. All $p$ values presented are two sided and values of $<0.05$ were considered to be statistically significant. Statistical analysis was performed using the Statistical Package for Social Sciences (version 12) (SPSS Inc., Chicago, IL, USA).

\section{Ethics}

The study protocol was approved by the Ethics Committee of Gifu University Graduate School of Medicine in advance. Each subject was explained the contents of the survey by letter and was allowed to refuse to answer any questions if he or she desired.

\section{Results}

The mean age and male/female ratio were significantly lower for hospital pharmacists than for prefectural officebased pharmacists (control group, $p<0.01$ ) (Table 1). There were no significant differences in the prevalence rate of medical histories relating to allergic diseases between hospital pharmacists and office-based pharmacists. Subjective symptoms were reported by $59.6 \%$ of hospital pharmacists and $60.5 \%$ of office-based pharmacists. The prevalence rate of nasal symptoms, namely, "sneezing, nasal discharge, or nasal obstruction", was significantly higher in hospital pharmacists $(33.1 \%)$ than in office-based pharmacists $(21.1 \%, p<0.05)$. The proportion of throat symptoms "uncomfortable feeling, itching, or pain in the throat" was $15.3 \%$ in hospital pharmacists and $6.6 \%$ in office-based pharmacists $(p=0.145)$. The prevalence rate for headache was significantly higher in office-based pharmacists than 
Table 2. Prevalence of nasal symptoms in hospital pharmacists categorized by work and working environments

\begin{tabular}{|c|c|c|c|c|c|c|c|c|c|c|}
\hline & \multicolumn{6}{|c|}{ Male } & \multicolumn{4}{|c|}{ Female } \\
\hline & \multicolumn{3}{|c|}{$\begin{array}{l}\text { With nasal } \\
\text { symptoms }\end{array}$} & \multicolumn{3}{|c|}{$\begin{array}{l}\text { Noticed symptoms after } \\
\text { starting drug compounding }\end{array}$} & \multicolumn{2}{|c|}{$\begin{array}{l}\text { With nasal } \\
\text { symptoms }\end{array}$} & \multicolumn{2}{|c|}{$\begin{array}{l}\text { Noticed symptoms after } \\
\text { starting drug compounding }\end{array}$} \\
\hline & $\mathrm{n}$ & $\%$ & & $\mathrm{n}$ & $\%$ & & $\mathrm{n}$ & $\%$ & $\mathrm{n}$ & $\%$ \\
\hline Total & 52 & 33.8 & & 21 & 13.6 & & 52 & 32.5 & 16 & 10.0 \\
\hline \multicolumn{11}{|l|}{ Main work } \\
\hline Drug compounding & 32 & 42.1 & & 14 & 18.4 & & 41 & 39.8 & 14 & 13.6 \\
\hline Ward pharmacy services & 8 & 20.0 & & 2 & 5.0 & & 8 & 18.6 & 1 & 2.3 \\
\hline Managements & 6 & 28.6 & & 3 & 14.3 & & 0 & 0.0 & 0 & 0.0 \\
\hline \multicolumn{11}{|l|}{ Clinical department mainly involved } \\
\hline Internal medicine & 45 & 34.1 & & 17 & 12.9 & & 46 & 33.6 & 15 & 10.9 \\
\hline Surgery & 27 & 29.3 & & 10 & 10.9 & & 25 & 29.4 & 9 & 10.6 \\
\hline Psychiatry & 13 & 61.9 & ** & 4 & 19.0 & & 17 & 38.6 & 4 & 9.1 \\
\hline Pediatrics & 12 & 37.5 & & 2 & 6.3 & & 17 & 42.5 & 5 & 12.5 \\
\hline Orthopedics & 23 & 32.9 & & 10 & 14.3 & & 19 & 30.2 & 5 & 7.9 \\
\hline Urology & 1 & 12.5 & & 1 & 12.5 & & 11 & 55.0 & 5 & 25.0 \\
\hline Otorhinolaryngology & 2 & 50.0 & & 2 & 50.0 & & 5 & 45.5 & 2 & 18.2 \\
\hline Ophthalmology & 8 & 61.5 & $*$ & 5 & 38.5 & $*$ & 4 & 33.3 & 2 & 16.7 \\
\hline \multicolumn{11}{|l|}{ Frequency of crushing tablets } \\
\hline Almost everyday & 17 & 41.5 & & 9 & 22.0 & & 20 & 40.8 & 8 & 16.3 \\
\hline Several times a week & 17 & 33.3 & & 7 & 13.7 & & 21 & 38.9 & 5 & 9.3 \\
\hline Several times a month & 8 & 25.8 & & 2 & 6.5 & & 8 & 25.0 & 2 & 6.3 \\
\hline Almost not & 8 & 30.8 & & 2 & 7.7 & & 2 & 8.7 & 0 & 0.0 \\
\hline \multicolumn{11}{|l|}{ Procedures for crushing tablets } \\
\hline Tablet crusher for exclusive use & 36 & 38.3 & & 17 & 18.1 & & 35 & 31.0 & 12 & 10.6 \\
\hline Domestic coffee mill & 4 & 25.0 & & 1 & 6.3 & & 7 & 35.0 & 1 & 5.0 \\
\hline Mortar & 31 & 31.3 & & 11 & 11.1 & & 34 & 33.0 & 13 & 12.6 \\
\hline Tablet cutter & 4 & 57.1 & & 2 & 28.6 & & 2 & 33.3 & 1 & 16.7 \\
\hline \multicolumn{11}{|l|}{ Frequency of opening capsules } \\
\hline Often & 8 & 57.1 & & 5 & 35.7 & $*$ & 9 & 52.0 & 3 & 17.6 \\
\hline Sometimes & 18 & 26.9 & & 6 & 9.0 & & 28 & 32.6 & 10 & 11.6 \\
\hline Almost not & 25 & 35.9 & & 9 & 12.9 & & 15 & 26.3 & 3 & 5.3 \\
\hline \multicolumn{11}{|c|}{$\begin{array}{l}\text { Use of masks during drug compound- } \\
\text { ing }\end{array}$} \\
\hline Always & 26 & 34.2 & & 8 & 10.5 & & 24 & 29.6 & 7 & 8.6 \\
\hline Sometimes & 15 & 42.9 & & 7 & 20.0 & & 21 & 42.9 & 5 & 10.2 \\
\hline Almost not & 10 & 24.4 & & 5 & 12.2 & & 7 & 23.3 & 4 & 13.3 \\
\hline \multicolumn{11}{|l|}{ Dust collector setting } \\
\hline With & 35 & 29.7 & & 11 & 9.3 & $* *$ & 42 & 35.6 & 13 & 11.0 \\
\hline Without & 15 & 50.0 & & 10 & 33.3 & ** & 8 & 24.2 & 2 & 6.1 \\
\hline \multicolumn{11}{|l|}{ Number of beds in hospital } \\
\hline Less than 300 & 24 & 44.4 & & 11 & 20.4 & & 22 & 34.9 & 5 & 7.9 \\
\hline 300 or over & 27 & 27.3 & & 9 & 9.1 & & 28 & 30.1 & 10 & 10.8 \\
\hline
\end{tabular}

${ }^{*} p<0.05,{ }^{* *} p<0.01$ vs. the other work-related categories by Mantel-Haenszel test categorized by age groups: $24-29,30-39,40-49$ and and $\geq 50$ yr.

in hospital pharmacists $(p<0.05)$.

The prevalence rates of nasal symptoms among hospital pharmacists, analyzed by taking into consideration working processes, working environments and gender, were higher in male pharmacists who mainly dispensed drugs for patients of the department of psychiatry or ophthalmology, and in female pharmacists who mainly engaged in drug compounding, drug dispensation for patients of the department of urology, and frequent crushing of tablets (more than several times a month) (Table 2). The 
Table 3. Prevalence of subjective symptoms noticed by hospital pharmacists (all hospital pharmacists and those mainly involved in drug compounding) and community pharmacists after the start of drug compounding

\begin{tabular}{|c|c|c|c|c|c|c|}
\hline & \multicolumn{3}{|c|}{ Male } & \multicolumn{3}{|c|}{ Female } \\
\hline & $\begin{array}{c}\text { Hospital } \\
\text { pharmacists }\end{array}$ & $\begin{array}{l}\text { Mainly drug } \\
\text { compounding }\end{array}$ & $\begin{array}{l}\text { Community } \\
\text { pharmacists }\end{array}$ & $\begin{array}{c}\text { Hospital } \\
\text { pharmacists }\end{array}$ & $\begin{array}{l}\text { Mainly drug } \\
\text { compounding }\end{array}$ & $\begin{array}{l}\text { Community } \\
\text { pharmacists }\end{array}$ \\
\hline Sneezing, nasal discharge, or nasal obstruction & $13.6 \%{ }^{* *}$ & $18.4 \%{ }^{* *}$ & $44.0 \%$ & $10.0 \%{ }^{* *}$ & $13.6 \%{ }^{* *}$ & $47.8 \%$ \\
\hline General fatigue & $4.5 \%$ & $9.2 \%$ & $7.7 \%$ & $3.8 \%{ }^{* *}$ & $4.9 \%{ }^{* *}$ & $7.0 \%$ \\
\hline An uncomfortable feeling, itching, or pain in the eyes & $3.9 \%{ }^{* *}$ & $6.6 \%{ }^{* *}$ & $21.4 \%$ & $6.9 \%{ }^{* *}$ & $6.8 \%{ }^{* *}$ & $15.3 \%$ \\
\hline An uncomfortable feeling, itching, or pain in the throat & $3.2 \%{ }^{* *}$ & $3.9 \%{ }^{* *}$ & $26.5 \%$ & $8.8 \%{ }^{* *}$ & $9.7 \%{ }^{* *}$ & $26.1 \%$ \\
\hline Headache & $1.9 \%$ & $2.6 \%$ & $6.0 \%$ & $1.9 \%$ & $1.9 \%$ & $5.7 \%$ \\
\hline Anxiety or helplessness & $1.9 \%$ & $3.9 \%$ & $5.6 \%$ & $1.9 \%$ & $1.9 \%$ & $5.1 \%$ \\
\hline Skin irritation, itching, or flare & $1.3 \% *$ & $2.6 \%$ & $6.4 \%$ & $5.6 \%$ & $5.8 \%$ & $8.9 \%$ \\
\hline $\begin{array}{l}\text { An uncomfortable feeling, itching, or pain in the oral } \\
\text { cavity }\end{array}$ & $1.3 \%{ }^{* *}$ & $2.6 \%$ & $9.8 \%$ & $3.8 \%{ }^{* *}$ & $2.9 \%{ }^{* *}$ & $14.0 \%$ \\
\hline Edema of the extremities & $1.3 \%$ & $2.6 \%$ & $1.7 \%$ & $1.9 \%$ & $1.9 \%$ & $1.9 \%$ \\
\hline Nausea, vomiting, abdominal pain, or diarrhea & $0.6 \%{ }^{*}$ & $0.0 \%$ & $2.6 \%$ & $1.3 \%$ & $1.9 \%$ & $2.5 \%$ \\
\hline A feeling of airway obstruction or dyspnea & $0.6 \%$ & $1.3 \%$ & $2.6 \%$ & $1.3 \%$ & $1.9 \%$ & $3.2 \%$ \\
\hline Numbness or dimmed vision & $0.6 \%$ & $1.3 \%$ & $1.3 \%$ & $0.6 \%$ & $1.0 \%$ & $0.6 \%$ \\
\hline Palpitation or chest discomfort & $0.6 \%$ & $1.3 \%$ & $1.7 \%$ & $0.6 \%$ & $1.0 \%$ & $1.3 \%$ \\
\hline Arthralgia & $0.0 \%$ & $0.0 \%$ & $4.7 \%$ & $0.6 \%$ & $0.0 \%$ & $5.1 \%$ \\
\hline Fever & $0.0 \%$ & $0.0 \%$ & $0.0 \%$ & $0.0 \%$ & $0.0 \%$ & $0.0 \%$ \\
\hline Other symptoms & $2.6 \%$ & $5.3 \%$ & $5.2 \%$ & $5.0 \%$ & $5.8 \%$ & $7.6 \%$ \\
\hline Without any symptoms & $74.7 \%{ }^{* *}$ & $63.2 \%^{* *}$ & $39.7 \%$ & $74.4 \%{ }^{* *}$ & $72.8 \%^{* *}$ & $28.7 \%$ \\
\hline
\end{tabular}

${ }^{*} p<0.05,{ }^{* *} p<0.01$ vs. community pharmacists by Mantel-Haenszel test categorized by age groups: $24-39,40-49$ and $\geq 50$ yr. Significant differences were not observed between the entire hospital pharmacist group and the sub-group of hospital pharmacists who engaged mainly in drug compounding work.

prevalence rates of nasal symptoms noticed after starting drug compounding were higher in male pharmacists who dispensed drugs for ophthalmology, who opened capsules frequently, and who worked in a dispensary lacking a dust collector. Significant difference in the prevalence rates of nasal symptoms were not observed between hospitals (data not shown).

The prevalence rates of the subjective symptoms that pharmacists noticed after starting drug compounding practices were compared between the total hospital pharmacists group, hospital pharmacists who engaged chiefly in drug compounding, and community pharmacists (Table 3 ). The percentages of eye, nasal, oral cavity, throat, skin, and gastrointestinal symptoms in male hospital pharmacists and those of eye, nasal, oral cavity, throat symptoms, and general fatigue in female hospital pharmacists were lower than the corresponding proportions in male and female community pharmacists. Symptoms of the eye, nose, and throat for male pharmacists and those of the eye, nose, oral cavity, and throat, and general fatigue, for female pharmacists also showed lower ratios in hospital pharmacists engaging chiefly in drug compounding work than in community pharmacists. Significant differences were not observed between the prevalence rates of symptoms in the entire hospital pharmacist group, compared to the subgroup of hospital pharmacists who engaged mainly in drug compounding work.

In term of the drug compounding processes and types of drugs that the pharmacists considered to be related to their subjective symptoms, the proportion of powder drug compounding processes and tablet crushing and/or capsule opening processes was high, and cardiovascular or respiratory drugs, psycho-neurological drugs, and antineoplastic drugs ranked highly (Table 4). The ratios of powder drug compounding processes, psycho-neurological drugs, and gastrointestinal drugs were lower in hospital pharmacists than in community pharmacists, and the ratio of antineoplastic drugs was higher in hospital pharmacists than in community pharmacists. The proportion of "unknown" for both drug compounding processes and types of drugs were higher in hospital pharmacists than in community pharmacists.

The most commonly adopted countermeasure against subjective symptoms in both hospital and community pharmacies was use of masks (Table 5). The effectiveness of mask use was reported to be $23.7 \%$ in hospital pharmacists and $10.7 \%$ in community pharmacists.

Self-rated job satisfaction levels were lower in male 
Table 4. Drug compounding processes and types of drugs that pharmacists considered to be related to their subjective symptoms

\begin{tabular}{lcc}
\hline & $\begin{array}{c}\text { Hospital pharmacists who noticed symptoms } \\
\text { after starting drug compounding } \\
(\mathrm{n}=80)\end{array}$ & $\begin{array}{c}\text { Community pharmacists who noticed symptoms } \\
\text { after starting drug compounding } \\
(\mathrm{n}=253)\end{array}$ \\
\hline Drug compounding process & $53.8 \%^{*}$ & $68.0 \%$ \\
Powder drug compounding & $47.5 \%$ & $51.0 \%$ \\
Tablet crushing or capsule opening & $1.3 \%$ & $2.8 \%$ \\
Ointment preparing & $21.3 \%$ & $15.4 \%$ \\
Other operations & $13.8 \%{ }^{*}$ & $5.9 \%$ \\
Unknown & & \\
\hline Types of drugs & $17.5 \%$ & $20.6 \%$ \\
Cardiovascular or respiratory drugs & $12.5 \%{ }^{* *}$ & $27.7 \%$ \\
Psycho-neurological drugs & $10.0 \%{ }^{* *}$ & $1.2 \%$ \\
Antineoplastic drugs & $6.3 \%$ & $11.9 \%$ \\
Antibiotics & $5.0 \%{ }^{* *}$ & $17.0 \%$ \\
Gastrointestinal drugs & $3.8 \%$ & $4.0 \%$ \\
Metabolic disease drugs & $2.5 \%$ & $4.3 \%$ \\
Decoctions & $1.3 \%$ & $6.7 \%$ \\
Antipyretics & $1.3 \%$ & $0.4 \%$ \\
Antirheumatic drugs & $1.3 \%{ }^{*}$ & $8.7 \%$ \\
Kampo herbal preparations & $12.5 \%$ & $17.4 \%$ \\
Other drugs & $51.3 \%{ }^{* *}$ & $22.1 \%$ \\
Unknown & & \\
\hline
\end{tabular}

${ }^{*} p<0.05,{ }^{* *} p<0.01$ vs. community pharmacists by Pearson's $\chi^{2}$ test

Table 5. Countermeasures against subjective symptoms

\begin{tabular}{|c|c|c|c|c|}
\hline & \multicolumn{2}{|c|}{$\begin{array}{l}\text { Hospital pharmacists } \\
\qquad(\mathrm{n}=80)\end{array}$} & \multicolumn{2}{|c|}{$\begin{array}{l}\text { Community pharmacists } \\
\qquad(\mathrm{n}=253)\end{array}$} \\
\hline & Adopted & Effective & Adopted & Effective \\
\hline Use of masks & $38(47.5 \%)$ & $9(23.7 \%)^{*}$ & $150(59.3 \%)$ & $16(10.7 \%)$ \\
\hline Improvement of equipment & $5(6.3 \%)$ & $1(20.0 \%)$ & $23(9.1 \%)$ & $2(8.7 \%)$ \\
\hline Change of working place & $1(1.3 \%)$ & $1(100.0 \%)$ & $5(2.0 \%)$ & $1(20.0 \%)$ \\
\hline Job replacement & $1(1.3 \%)$ & $0(0.0 \%)$ & $12(4.7 \%)$ & $2(16.7 \%)$ \\
\hline Other measures & $11(13.8 \%)$ & $2(18.2 \%)$ & $32(12.6 \%)$ & $1(3.1 \%)$ \\
\hline Nothing done & $30(37.5 \%)$ & $-(-)$ & $72(28.5 \%)$ & $-(-)$ \\
\hline
\end{tabular}

${ }^{*} p<0.05$ vs. community pharmacists by Pearson's $\chi^{2}$ test

hospital pharmacists than in male office-based pharmacists or community pharmacists (Table 6). The proportion of "satisfied" and "somewhat satisfied" was lower in hospital pharmacists after adjustment for sex- and age-group by the Mantel-Haenszel procedure $(p<0.01) ; 69.6 \%$ of hospital pharmacists, and $86.8 \%$ of office-based pharmacists and $80.7 \%$ of community pharmacists answered "satisfied" or "somewhat satisfied" with work, respectively, with no significant difference between male and female respondents.

The proportion of hospital pharmacists who replied as "satisfied" or "somewhat satisfied" with work was lower in those with nasal symptoms, general fatigue, or headache (Table 7). This proportion was also lower in hospital pharmacists who had noticed nasal symptoms since starting drug compounding work, compared to pharmacists without these symptoms.

\section{Discussion}

Subjective symptoms were reported by about $60 \%$ of both hospital pharmacists and prefectural office-based pharmacists who did not engage in drug compounding. 
Table 6. Levels of job satisfaction in hospital pharmacists, office-based pharmacists and community pharmacists

\begin{tabular}{|c|c|c|c|c|}
\hline & Satisfied & Somewhat satisfied & Somewhat dissatisfied & Dissatisfied \\
\hline \multicolumn{5}{|l|}{ Men } \\
\hline Hospital pharmacists* & $6.0 \%$ & $62.9 \%$ & $24.5 \%$ & $6.6 \%$ \\
\hline Office-based pharmacists & $8.6 \%$ & $79.3 \%$ & $8.6 \%$ & $3.4 \%$ \\
\hline Community pharmacists & $27.0 \%$ & $53.6 \%$ & $13.7 \%$ & $5.6 \%$ \\
\hline \multicolumn{5}{|l|}{ Women } \\
\hline Hospital pharmacists & $5.7 \%$ & $64.6 \%$ & $24.1 \%$ & $5.7 \%$ \\
\hline Office-based pharmacists & $5.6 \%$ & $77.8 \%$ & $16.7 \%$ & $0.0 \%$ \\
\hline Community pharmacists & $24.5 \%$ & $56.1 \%$ & $14.8 \%$ & $4.5 \%$ \\
\hline \multicolumn{5}{|l|}{ Total } \\
\hline Hospital pharmacists* & $5.8 \%$ & $63.8 \%$ & $24.3 \%$ & $6.1 \%$ \\
\hline Office-based pharmacists & $7.9 \%$ & $78.9 \%$ & $10.5 \%$ & $2.6 \%$ \\
\hline Community pharmacists & $26.0 \%$ & $54.6 \%$ & $14.2 \%$ & $5.2 \%$ \\
\hline
\end{tabular}

${ }^{*} p<0.05$ vs. office-based pharmacists and community pharmacists by contingency table.

Table 7. Proportion of hospital pharmacists satisfied with works analyzed by the presence or absence of subjective symptoms

\begin{tabular}{lccc}
\hline & Without symptoms & With symptoms & $\begin{array}{c}\text { Noticed symptoms after } \\
\text { starting drug compounding }\end{array}$ \\
\hline Sneezing, or nasal discharge or obstruction & $73.6 \%$ & $61.4 \%^{*}$ & $57.1 \%^{*}$ \\
General fatigue & $72.8 \%$ & $48.8 \%{ }^{* *}$ & $61.5 \%$ \\
Headache & $72.2 \%$ & $56.0 \%{ }^{*}$ & $66.7 \%$ \\
An uncomfortable feeling, itching, or pain in the eyes & $71.2 \%$ & $63.6 \%$ & $70.6 \%$ \\
Skin irritation, itching, or flare & $71.1 \%$ & $56.3 \%$ & $50.0 \%$ \\
An uncomfortable feeling, itching, or pain in the throat & $70.5 \%$ & $64.4 \%$ & $64.7 \%$ \\
An uncomfortable feeling, itching, or pain in the oral cavity & $70.4 \%$ & $59.1 \%$ & $71.4 \%$ \\
\hline
\end{tabular}

${ }^{*} p<0.05,{ }^{*} p<0.01$ vs. pharmacists without corresponding symptoms by Mantel-Haenszel test categorized by sex- and age-groups: 24-39, $40-49$ and $\geq 50 \mathrm{yr}$.

The prevalence rates of nasal symptoms were significantly higher in hospital pharmacists; furthermore, the prevalence rate of throat symptoms also tended to be higher in this group. These results were similar to those for the symptoms previously reported in community pharmacists involved in drug compounding ${ }^{4)}$. These symptoms suggest allergies or irritation of the mucous membranes. If these symptoms are related to drug compounding processes, the prevalence rates of symptoms may be differ depending on the drugs handled or the extent of exposure to drug dust. On the other hand, the prevalence rate of headache was higher in pharmacists engaging in office work than in hospital pharmacists. Because office-based pharmacists also showed a tendency towards higher prevalence of eye symptoms, the effects of visual display terminals (VDT) and working posture should be considered ${ }^{16)}$.

Among hospital pharmacists, the prevalence rate of nasal symptoms was higher in those engaged mainly in drug compounding, and lower in those engaged mainly in ward pharmacy services. A higher frequency of crushing tablets or opening capsules tended to be related to nasal symptoms. These results also suggested an influence of drug compounding practices on subjective symptoms. The prevalence rates of symptoms also tended to be higher in those using tablet cutters and in those working in small hospitals with less than 300 beds, where pharmacists' roles beyond drug compounding work are more limited. Differences in nasal symptom prevalence rates by clinical department, drug compounding processes, and dispensary environments should be investigated further by sampling dispensary drug dust.

The prevalence rates of subjective symptoms that pharmacists noticed after starting drug compounding work were lower in hospital pharmacists than in community pharmacists. These rates were also lower in the hospital pharmacist group, after exclusion of those whose main role did not include drug compounding. These results suggested that exposure to drug dust is lower in hospital phar- 
macists than in community pharmacists and differences in working procedures and working environments between the hospital pharmacy dispensary and the community pharmacy dispensary should therefore be investigated.

About half of both hospital pharmacists and community pharmacists considered it likely that their subjective symptoms were related to powder drug compounding and tablet crushing and/or capsule opening. These results suggested aspiration of drug dust in the dispensary. When considering the drug groups likely to be involved, hospital pharmacists were less likely to refer to psycho-neurological and gastrointestinal drugs than community pharmacists. On the other hand, hospital pharmacists were more likely to refer to antineoplastic drugs than community pharmacists were. These results reflect the differentiation and specialization of medical services. Deleterious effects of psychoneurological drugs via allergic mechanisms have also been reported previously ${ }^{17-19)}$. The frequency of the reply "drugs unknown" was higher in hospital pharmacists. This may be because hospital pharmacists deal with so many kinds of drugs that they were not able to identify a particular culprit.

The symptoms listed in this study may be induced also as sick building syndrome ${ }^{20,21)}$. However, the prevalence rates of symptoms were not significantly different between hospital including new and old facilities. In many hospitals, relative humidity in dispensing room is controlled by ordinal air-conditioner, and is about $50 \%$. Therefore, we thought that sick building syndrome was not mainly involved in the symptoms.

The limitation of this study is that in this study, we investigated the prevalence rates of subjective symptoms in pharmacists, but not those of objective signs. Although the subject of this study is health care professionals, influences of their assumptions or prejudices on their subjective symptoms cannot be excluded. In the following studies, we must compare the concentration of drug dust in dispensaries between hospitals, before and during drug compounding processes such as powder drug handling, tablet crushing and capsule opening, and with or without dust collector. Measurement of concentrations of compounding drugs in blood may also be useful.

Use of masks was the most frequently adopted countermeasure against subjective symptoms, but the effectiveness of masks was not high. Although the type of masks was not asked in this questionnaire, surgical masks are widely used in hospital and community pharmacies. Proper countermeasures should be introduced by measuring the size of drug dust particles and especially airflow in the dispensary ${ }^{22,23)}$.

Self-rated job satisfaction levels were lower in hospital pharmacists than in office-based pharmacists or community pharmacists, even after age-adjustment. Prevalence rates of subjective symptoms were lower in hospital pharmacists than in community pharmacists, although hospital pharmacists with subjective symptoms showed the lowest work satisfaction level. There was no clear influence of subjective symptoms on job satisfaction. Other factors, such as perception of job importance, perceived utilization of skills, job autonomy, job atmosphere, and staffing should be included in another analysis ${ }^{24,25)}$.

Additional surveys within the dispensary to assess working processes and working environments are needed to adopt effective countermeasures to reduce the occupational exposure of pharmacists to drug dust ${ }^{22,26)}$.

\section{Acknowledgements}

The present study was supported by JSPS KAKENHI Grant Number 24659319 (Grant-in-Aid for Challenging Exploratory Research from Japan Society for the Promotion of Science). The authors thank all the study subjects for their cooperation and Ms. Mayumi Okumura for her data arranging.

\section{References}

1) Sekimoto H, Wada K, Nakamura K, Kobayashi M, Morishita H (2010) Contribution to proper use of medicines and safety of medical treatment made by resident pharmacists in wards. Iryo Yakugaku 36, 171-9 (Jpn J Pharm Health Care Sci).

2) Tokunaga J, Setoguchi N, Koinuma M, Nakanishi N, Ogata K, Matsuoka T, Sato K, Nakamura H, Takamura N (2011) A comparison of consciousness about a pharmacist's duties between hospital and community pharmacists based on questionnaire analysis with discussion. Nihon Byoin Yakuzaishi Kai Zasshi 47, 185-9 (J Jpn Soc Hosp Pharm).

3) Nakamura $T$ (2009) [Review of studies on the role of community pharmacy in dispensing practice-change on the 30-year study]. Yakushigaku Zasshi 44, 56-63 (in Japanese). [Medline]

4) Inaba R, Kondo Y, Hioki A (2012) Health problems related to drug compounding of pharmacists in dispensing pharmacies. Nippon Shokugyo Saigai Igakkai Kaishi 60, 23-31 (JJOMT).

5) Nakamura S (1971) [Studies on asthma bronchiale. 6. On the occupational allergy caused by pancreatin among pharmacists]. Arerugi 20, 361-4 (in Japanese). [Medline]

6) Nishii S, Yamaji A, Kishi H, Hiraoka E, Miyamoto H, 
Matsunaga T (1984) Survey on the drug dust induced nasal allergies in hospital pharmacy. Nihon Byoin Yakuzaishi Kai Zasshi 20, 1045-8 (J Jpn Soc Hosp Pharm).

7) NIOSH (1997) NIOSH alert: preventing occupational exposure to antineoplastic and other hazardous drugs in health care settings, DHHS (NIOSH) Publication No. 2004-165. U.S. Department of Health and Human Services, Centers for Disease Control and Prevention, National Institute for Occupational Safety and Health, Cincinnati.

8) Tomioka K, Kumagai S (2005) [Health risks of occupational exposure to anticancer (antineoplastic) drugs in health care workers]. Sangyo Eiseigaku Zasshi 47, 195-203 (in Japanese with English abstract). [Medline] [CrossRef]

9) Sugiura S, Nakanishi H, Asano M, Hashida T, Tanimura M, Hama T, Nabeshima T (2011) Multicenter study for environmental and biological monitoring of occupational exposure to cyclophosphamide in Japan. J Oncol Pharm Pract 17, 20-8. [Medline] [CrossRef]

10) Landeck L, Skudlik C, John SM (2012) Airborne contact dermatitis to tetrazepam in geriatric nurses - a report of 10 cases. J Eur Acad Dermatol Venereol 26, 680-4. [Medline] [CrossRef]

11) Minciullo PL, Imbesi S, Tigano V, Gangemi $\mathrm{S}$ (2013) Airborne contact dermatitis to drugs. Allergol Immunopathol (Madr) 41, 121-6. [Medline] [CrossRef]

12) Kim JE, Kim SH, Jin HJ, Hwang EK, Kim JH, Ye YM, Park HS (2012) IgE sensitization to cephalosporins in health care workers. Allergy Asthma Immunol Res 4, 85-91. [Medline] [CrossRef]

13) Ministry of Health, Labour and Welfare (2012) Summary of Patient Survey, 2011, 19-20, Ministry of Health and Welfare, Tokyo.

14) Akishita M, Ouchi Y, Toba K, Mizuno Y, Wada H, Mizoguchi T, Hattori A, Nakamura T, Fukuchi Y, Orimo H (1995) [Compliance with prescriptions and adverse drug reactions in the elderly]. Nippon Ronen Igakkai Zasshi 32, 178-82 (in Japanese with English abstract). [Medline] [CrossRef]

15) Japan Meteorological Agency Climate Statistics. http:// www.data.jma.go.jp/obd/stats/etrn/index.php. Accessed August 24, 2013.

16) Nakazawa $T$, Okubo Y, Suwazono $Y$, Kobayashi E, Komine S, Kato N, Nogawa K (2002) Association between duration of daily VDT use and subjective symptoms. Am J Ind Med 42, 421-6. [Medline] [CrossRef]

17) Maki Y (1976) Occupational allergy in pharmacy. Gekkan Yakuji 18, 81-7 (Pharmaceuticals Monthly).

18) Torinuki W (1995) Contact dermatitis to biperiden and photocontact dermatitis to phenothiazines in a pharmacist. Tohoku J Exp Med 176, 249-52. [Medline] [CrossRef]

19) Zacharisen MC (2002) Occupational asthma. Med Clin North Am 86, 951-71. [Medline] [CrossRef]

20) Redlich CA, Sparer J, Cullen MR (1997) Sick-building syndrome. Lancet 349, 1013-6. [Medline] [CrossRef]

21) Takigawa $T$, Wang BL, Saijo Y, Morimoto K, Nakayama K, Tanaka M, Shibata E, Yoshimura T, Chikara H, Ogino K, Kishi R (2010) Relationship between indoor chemical concentrations and subjective symptoms associated with sick building syndrome in newly built houses in Japan. Int Arch Occup Environ Health 83, 225-35. [Medline] [CrossRef]

22) Hayashi H, Akita M, Kondo G, Suhara K (1980) Reduction in number of dust particles by vacuum cleaner. Byoin Yakugaku 6, 220-6 (Jpn J Hosp Pharm).

23) Tomonaga F, Kobayashi T, Minezawa Y, Asami T, Motohashi S, Konishi Y (1983) Comparison of different air samplers for monitoring dust in the drug preparation room. Byoin Yakugaku 9, 195-9 (Jpn J Hosp Pharm).

24) Cox ER, Fitzpatrick V (1999) Pharmacists' job satisfaction and perceived utilization of skills. Am J Health Syst Pharm 56, 1733-7. [Medline]

25) Carvajal MJ, Hardigan PC (2000) Pharmacists' sources of job satisfaction: inter-gender differences in response. Am $\mathrm{J}$ Pharm Educ 64, 420-5.

26) Takayama K, Seino T, Sugiura M, Nakamura H, Uchino K, Nakamura K, Sato H, Iga T (1999) Quantitative analysis of air cleanness in the dispensing environment: introduction and evaluation of a dust-free dispensing facility. Yakugaku Zasshi 119, 429-35 (in Japanese with English abstract). 